\title{
FRAY COELLO DE PORTUGAL Y SU ARQUITECTURA EN ZAMORA
}

\author{
FRAY COELLO DE PORTUGAL AND HIS \\ ARCHITECTURE IN ZAMORA
}

\author{
RAFAel Ángel García-LozAno \\ Universidad Pontificia de Salamanca. España \\ ORCID: 0000-0003-4913-7019 \\ ragarcialo@upsa.es
}

\begin{abstract}
Abordamos en este trabajo el proceso de creación de una importante arquitectura diseñada por el arquitecto dominico Fray Coello de Portugal y Acuña para Zamora. Realizada al filo de la reforma del Concilio Vaticano II (1962-1965), el Colegio Divina Providencia adoptó en sus espacios sacros las nuevas determinaciones litúrgicas emanadas de este sínodo, así como el lenguaje estilístico fruto de la renovación arquitectónica española de la época. A pesar del generalizado desconocimiento de este centro, el edificio se establece como una de las obras contemporáneas más representativas de ciudad, y su capilla como una de las creaciones más destacables de quien fuera el arquitecto español del siglo XX autor del mayor número de arquitecturas religiosas en el país.

Palabras clave: Fray Francisco Coello de Portugal y Acuña; arquitectura escolar; arquitectura religiosa contemporánea; arte sacro; Zamora.
\end{abstract}

In this work we study the process of creating one important architecture designed by the Dominican architect Fray Coello de Portugal y Acuña for Zamora. It was designed at the time of the Second Vatican Council (1962-1965), Divina Providencia School and its sacred spaces took the new liturgical rules established by this synod, as well as the stylistic language resulting from the Spanish architectural renovation of the time. In spite of the general lack of knowledge about this centre, the building is established as one of the most representative contemporary works of the city, and its chapel as one of the most remarkable work of this architect. Coello was the 20th century spanish architect whith the largest number of religious architectures in the country.

Keywords: Francisco Coello de Portugal y Acuña; school architecture; contemporary religious architecture; sacred art; Zamora. 


\section{LOS ORÍGENES HISTÓRICOS}

La permanencia en Zamora de la congregación de las Siervas de San José en la calle de La Reina número 11 se ha mantenido constante desde que fuera donada a la orden el 26 de abril de 1889 por el obispo Tomás Belestá y Cambeses ${ }^{1}$. Con aquella entrega se hizo posible que las religiosas fijasen su residencia definitiva junto a la capilla de Nuestra Señora de La Candelaria, cuya cesión había solicitado al prelado la superiora de la comunidad y conseguido en $1885^{2}$. Este establecimiento resultó determinante después de haber pasado hasta por hasta cuatro residencias más en los seis años de estancia en la diócesis, además de unificar su vivienda y un lugar de oración. Esta capilla se ubicaba en la calle Candelaria Ruiz del Árbol -actual Corral Pintado- haciendo esquina con la calle La Reina, pertenecía a la jurisdicción parroquial de Santa María la Nueva ${ }^{3}$ y tenía su origen en el siglo XIV ${ }^{4}$. En sus inicios había formado parte de un hospital fundado por la cofradía homónima, que atendía a enfermos pobres de solemnidad ${ }^{5}$ En sus dependencias se instalaron los jesuitas a instancias del obispo Francisco Zapata Vera y Morales entre 1712 y $1716^{6}$. Posteriormente la propiedad pasó a la Cofradía de Caballeros de San Ildefonso ${ }^{7}$, y desde 1848 los Hermanos de la Escuela de Jesús y María se hicieron con el oratorio el 9 de julio de 1851 gracias al obispo Rafael Manso y Manso ${ }^{8}$. Después de tres décadas la capilla quedó sin uso en 1879, lo que acentuó su progresivo deterioro hasta que las Siervas de San José se hicieron cargo de ella, sometiéndola a unas obras de reparación integral entre noviembre de 1894 y febrero de 1895 bajo la responsabilidad del arquitecto Segundo Viloria y Escarda ${ }^{9}$.

${ }^{1}$ Archivo Diocesano de Zamora (ADZa), Curia, 1966, H. 20. Contrato, de 15 de julio de 1966. Véase también Boletín Oficial del Obispado de Zamora 28 (1890) 146.

${ }^{2}$ De Cáceres Sevilla, 1981: 193-6. En esta obra se asegura que la capilla era ya propiedad de las religiosas en 1885, aunque también se afirma que la petición se realizó formalmente al obispo el 1 de marzo de 1888. No hemos encontrado ninguna referencia a este particular en los años citados en la documentación depositada en el ADZa, del mismo modo que la documentación más reciente tampoco explicita la fecha exacta o aproximada de la donación del templo. ADZa, Curia, 1964, D. 8 y 1966, H. 20.

3 Gómez Carabias, 1884: 327.

${ }^{4}$ Hernández Fuentes/Mateos Carretero, 2005: 39.

5 Piñuela Ximénez, 1987: 215.

${ }^{6}$ García-Lozano, 2012: 226. Piñuela Ximénez, 1987: 215.

7 García-Lozano, 2010: 59-64. Esta institución realizó obras de mejora en la capilla e instaló un nuevo retablo y un nuevo cancel, trabajos inaugurados el 24 de septiembre de 1803. Piñuela Ximénez, 1987: 215-216.

${ }^{8}$ De Cáceres Sevilla, 1981: 194. Fue entonces cuando se segregaron el espacio religioso y la casa contigua. Piñuela Ximénez, 1987: 215.

9 Archivo Histórico Diocesano de Zamora (AHDZa), Secretaría de Cámara, 85/7. 
La capilla tenía planta poligonal tendente al rectángulo y estaba orientada hacia el Este según las normas litúrgicas entonces vigentes. El eje de la nave estaba fragmentado en tres partes cambiando de dirección, conformando un espacio formado por otros tres tramos, solamente el más cercano al presbiterio enmarcado por un arco de medio punto. Volteaba una sencilla bóveda semiesférica de escayola sobre pechinas, el presbiterio ocupaba parcialmente este tramo y su espacio estaba elevado sobre la cota de la nave. Contaba con un sencillo altar y un retablo de madera instalado a comienzos del siglo XIX formado por tres calles, un cuerpo y ático, así como púlpito y tornavoz de madera y antepecho de hierro. A los pies se alzaba una tribuna sustentada sobre pilares a la que se accedía desde la casa contigua, donde también existía una sacristía. La ermita estaba interiormente decorada formando despiece, poseía algunos lienzos en los muros y un Cristo crucificado gótico tallado en madera algo menor del tamaño natural en el coro, así como unas imágenes de San José, Jesucristo y la Virgen María. Exteriormente sólo una sencilla portada labrada en piedra formando una arquivolta de medio punto con bolas sobre sendas columnas enmarcaba el acceso al templo y denotaba la condición sagrada del inmueble. Sobre ésta existía una hornacina y a ambos lados sendos vanos formados por arcos escarzanos recercados en piedra.

Con la instalación de las Siervas de San José ${ }^{10}$, en el primer piso de la casa se creó un taller de bordados y ornamentos textiles con el que ofrecieron educación integral a buen número de niñas y jóvenes huérfanas pobres. Fiel al carisma fundacional, la casa acogió poco después el Colegio de Desamparadas ${ }^{11}$, que fue ampliándose progresivamente con la adquisición de algunas fincas limítrofes, siendo el origen del colegio Divina Providencia.

\section{ENCARGO A UN ARQUITECTO REFERENTE}

Tras el frustrado intento de construcción de un colegio de nueva planta junto a la ermita del Carmen del Camino, las Siervas de San José abrieron en octubre 1942 el colegio San José en la avenida Italia, que hasta entonces había pertenecido a los hermanos Roldán Prieto. Las religiosas trasladaron a ese centro el internado de la calle La Reina por encontrarse el edificio en malas condiciones, pero decidieron reabrir inmediatamente un nuevo internado en ese inmueble con el fin de acoger a niñas socorridas por el Patronato de Redención de Penas por el Trabajo ${ }^{12}$. La congregación puso esta infraestructura al servicio de la Junta

${ }^{10}$ De Cáceres Sevilla, 1981: 204.

${ }^{11}$ El centro socorría en régimen de asilo a muchachas de la misma extracción social, ofreciéndoles educación por la participación en el trabajo, además de enseñarles a leer y escribir. De Cáceres Sevilla, 1981: 206-213.

${ }^{12}$ Información aportada por la Sierva de San José Manuela Miguel Gallego en una entrevista celebrada el 2 de octubre de 2012. 
de Protección de Menores e inició los trámites para la creación y consolidación de una escuela hogar ${ }^{13}$. Durante dos décadas más el colegio de la calle La Reina prosiguió su actividad asistencial, a pesar de que en los primeros años sesenta su estado era ya lastimoso. Las razones que justificaron la promoción de la construcción de un nuevo colegio fueron "el gran deterioro y escasa capacidad existente [en las instalaciones]" 14 , dado que el centro estaba formado por viejas casas donadas o compradas en diferentes momentos y que habían sido interconectadas sin lograr un conjunto articulado. El penoso estado de estos inmuebles hizo que la propiedad afianzase la decisión de emprender la demolición del conjunto, medida que, con la anuencia de la administración oficial, denotó escasa valoración de la arquitectura preexistente, especialmente en lo concerniente a la capilla de La Candelaria ${ }^{15}$.

Para esta iniciativa la congregación estableció contacto con el arquitecto y dominico Francisco Coello de Portugal y Acuña, quien accedió a la redacción del proyecto de nuevo colegio y residencia. Nacido en Jaén en 1926, se tituló como arquitecto en 1953 por la escuela de Madrid, tras haber pasado previamente por la de Barcelona. En 1954 inició su trabajo en la Oficina de la Dirección General de Regiones Devastadas en Córdoba ${ }^{16}$, ingresando en junio de ese mismo año en el noviciado dominico de Palencia. El 10 de junio de 1955 emitió su primera profesión religiosa, el mismo día de 1958 hizo su profesión solemne y el 23 de julio de 1961 fue ordenado sacerdote ${ }^{17}$. Sólo un año después de su ingreso en la orden, en 1955 su provincial le pidió la proyección de un seminario menor, convento y santuario en La Virgen del Camino (León), resultando su obra primigenia y la que, por su envergadura, lenguaje y conciliación entre tradición y modernidad, lo consagró $^{18}$. Inició así una carrera profesional con más de 300 obras entre iglesias, monasterios y colegios repartidos por España, Italia, Reino Unido, Angola, Venezuela, Bolivia, Colombia, Méjico, Puerto Rico, Antillas Holandesas, Corea del Sur y Taiwan ${ }^{19}$, siendo el arquitecto español con mayor producción religiosa del siglo XX. Su arquitectura sagrada quedó encuadrada por algunos autores dentro del funcionalismo constructivista y comúnmente singularizada por su habitual

${ }^{13}$ Información aportada por Manuela Miguel Gallego en una entrevista celebrada el 5 de octubre de 2012.

${ }^{14}$ Archivo Municipal de Zamora (AMZa), Obras y Urbanismo (OyU), OM/615/68, Expediente administrativo, Solicitud de autorización de obras, de 24 de junio de 1966.

${ }^{15}$ La portada de la antigua capilla fue trasladada a la localidad zamorana de Pajares de la Lampreana, en cuya iglesia fue nuevamente instalada. Promovió este traslado Manuela Miguel Gallego, natural de esa población.

16 Fernández-Cobián, 2001: 11.

${ }^{17}$ Información aportada por el secretario de la provincia dominica de España, Óscar Jesús Fernández, en una entrevista celebrada el 18 de septiembre de 2015.

${ }_{18}$ Delgado Orusco, 2009: 321-329. Otxotorena Elizegi, 2006: 10 ss.

19 Coello de Portugal, 2005: 16 ss. 
empleo del hormigón ${ }^{20}$, aspectos concretados en el predominio de planos lisos y la línea recta, así como la amplitud de los espacios, el protagonismo del vacío, el empleo de la luz como el material esencial en sus arquitecturas, la sobriedad decorativa y la racionalidad de sus soluciones. Si bien estas propuestas acabaron extendiéndose como características de la mejor arquitectura moderna aplicada a su especificidad sagrada, Coello imprimió un especial desarrollo en cuanto a la modulación del espacio, la ponderación y austeridad de sus arquitecturas religio$\operatorname{sas}^{21}$, la esencialidad formal y, con ellas, la modernización en el lenguaje sacro ${ }^{22}$. Consiguió, consecuentemente, una sobresaliente potencia icónica en sus diseños, que lo situaron como genuino renovador de la arquitectura religiosa contemporánea entre sus colegas, reconocimiento que fue también posible gracias a su extraordinaria nómina de creaciones, no alcanzada por ningún contemporáneo en nuestro país. Además de La Virgen del Camino destacan el monasterio de Santa Inés en Zaragoza (1962), el colegio San Martín de Porres en Granada (1962), el centro de Promoción Social en Madrid (1964), en Torrelavega los colegios de los Sagrados Corazones (1964) y Nuestra Señora de la Paz (1964), el colegio Santo Domingo de Guzmán en Palencia (1965), el monasterio de Santa Catalina de Siena en Alcobendas (1965) y la iglesia de Nuestra Señora del Valle en Becerril de la Sierra (1965). Sobresalen fuera de nuestro país el colegio Santo Domingo de Guzmán en El Rosa-Caracas (1983), la iglesia de Nuestra Señora del Rosario en Yauco (Puerto Rico) (1984), el monasterio de la Madre de Dios en Curaçao (Antillas Holandesas) (1989), el monasterio de la Madre de Dios en Tierra Santa (Corea del Sur) (1990), la catedral de San Juan evangelista en Chiayi (Taiwan) ${ }^{23}$ y la iglesia de las jesuitinas en Metoro (Mozambique) (2009) ${ }^{24}$. Tras recibir varios reconocimientos de la Real Academia de Bellas Artes (1994) y de Academia de Doctores (2007) entre otros, falleció en Madrid el 16 de agosto de 2013.

La elección del padre Coello por las Siervas de San José de Zamora no vino dada únicamente por su competencia probada ya en los cinco proyectos de carácter religioso que había redactado hasta entonces, sino también tras valorar positivamente su condición de sacerdote y religioso dominico, que le hacía directo conocedor de las implicaciones no sólo arquitectónicas de una obra de estas características ${ }^{25}$. Asimismo fue también elegido por su vinculación con la

${ }^{20}$ Urrutia, 1997: 311.

${ }^{21}$ Delgado Orusco, 2009: 327.

${ }^{22}$ Fernández-Cobián, 2005: 429-430.

${ }^{23}$ Fernández-Cobián, 2001: 268-275.

${ }^{24}$ Información aportada por el padre Francisco Coello de Portugal y Acuña en una entrevista celebrada el 26 de diciembre de 2012.

${ }^{25}$ El arquitecto había realizado un profundo estudio analítico de la tradición arquitectónica de la vida religiosa, especialmente centrado en la orden fundada por Santo Domingo de Guzmán. Iturgaiz Ciriza, 2001: 62-64. También demostró una especial sensibilidad con 
congregación, para la que ya había redactado otros proyectos en España ${ }^{26}$. Las comitentes trasladaron al arquitecto las peculiaridades del centro e insistieron en el talante caritativo de la institución, con el fin de que el diseño del inmueble se adaptase adecuadamente ${ }^{27}$. El padre Coello rubricó el proyecto en julio de 1964. Por su parte, las religiosas emprendieron los trámites necesarios para la construcción del edificio, designado centro benéfico social Divina Providencia, abordando primeramente las transacciones económicas necesarias para redimir las condiciones del contrato de donación de la casa efectuado por el obispo Belestá y Cambe$\operatorname{ses}^{28}$. A tenor de éstas, las Siervas de San José no podían disponer de la casa de la calle La Reina número 11 para su derribo, por lo que monseñor Martínez González y la superiora provincial de la congregación, Celina Reboredo García, llegaron a un acuerdo por el que convinieron que las religiosas revirtieran al obispado la propiedad de dicha casa ${ }^{29}$ y seguidamente solicitaron la cesión de los solares ubicados en la calle La Reina número 9 y el contiguo a la capilla de La Candelaria, ambos de propiedad diocesana, que le fue concedida ${ }^{30}$. Poco después las religiosas recibieron el solar de la calle La Reina número 11 y el de la capilla como cesión episcopal ${ }^{31}$. Incorporaron también una nueva finca adquirida a los hermanos Fernández Domínguez, logrando así aglutinar un conjunto suficiente de solares para llevar a cabo sus fines benéfico-docentes ${ }^{32}$.

\section{LA ARQUITECTURA DEL CENTRO EDUCATIVO}

El solar surgido del derribo de los antiguos edificios y sobre el que se proyectó el nuevo colegio y residencia tenía una forma irregular y estaba enclavado en pleno casco antiguo de la ciudad, condicionantes que influyeron de forma notable en el resultado del proyecto. (Figura 1). Sin embargo, dos circunstancias determinaron plenamente el inmueble y se impusieron como criterios de indispensable

los condicionantes interpuestos por las religiosas, la integración de la celda de la fundadora y la una parte de la capilla donde se depositaron documentos de extraordinario valor para la congregación. Archivo Histórico Provincial de Zamora (AHPZa), Delegación Provincial de la Vivienda (DPV), 70/24, Memoria, 1, 2 y 4.

${ }^{26}$ Información aportada por Manuela Miguel Gallego en una entrevista celebrada el 9 de octubre de 2012.

27 AHPZa, DPV, 70/24, Memoria, 1.

28 ADZa, Curia, 1964, D. 8 y 1966, H. 20.

29 ADZa, Curia, 1966, H. 20, Carta, de 21 de febrero de 1966 y Oficio, de 10 de marzo de 1966.

30 ADZa, Curia, 1966, H. 20, Oficio, de 13 de marzo de 1966.

31 ADZa, Curia, 1966, H. 20, Oficio, de mayo de 1966. Se compensaron con 500.000 pesetas las renuncias y cesiones realizadas por éste en su favor. ADZa, Curia, 1966, H. 20, Contrato, de 15 de julio de 1966, 2.

${ }^{32}$ ADZa, Curia, 1966, H. 20, Contrato, de 15 de julio de 1966, 3. 
salvaguarda: la conservación del lugar donde habían aparecido algunos documentos fundacionales de la congregación y la que fue celda de la fundadora de la misma ${ }^{33}$. Partiendo de estas premisas y condicionado por la forma de la finca, Francisco Coello ideó un único bloque que agrupaba todas las necesidades, dejando el espacio restante reservado a campo de juegos y una pequeña granja, además de vivienda para su encargado ${ }^{34}$. El inmueble tiene planta longitudinal, en cuyo extremo Suroeste insertó un cuerpo donde dispuso, superpuestos, el salón de actos y la capilla del colegio. El edificio se adapta a la alineación de la calle La Reina gracias a un quiebro en la parte central y donde el colegiado dispuso una escalera para la comunicación vertical. (Figura 2). Inicialmente el bloque estaba concebido con cuatro plantas más ático y semisótano, y dotado de cierta separación entre el colegio e internado y la residencia de religiosas ${ }^{35}$. El arquitecto incluyó una escalera en el extremo Sur de uso exclusivo de la comunidad, comunicando el refectorio y cocinas en el semisótano, los despachos y capilla en la planta baja, las salas de comunidad de las plantas primera y segunda y sus dormitorios y dependencias ubicadas en el ático ${ }^{36}$. Por otro lado, dispuso el comedor de las residentes y el salón de actos en el semisótano, la sala de estar del colegio en la planta baja y dedicó dos plantas para aulas y dos más para dormitorios a modo de celdillas $^{37}$. Cada una de las plantas dispone de un pasillo paralelo a la fachada de la calle La Reina para el acceso tanto a las aulas como a los dormitorios.

La fachada principal a la calle La Reina es marcadamente horizontal, y se yergue sobre un muro de hormigón a modo de zócalo que cierra la planta baja. Sobre éste se alza la fábrica de ladrillo de color pajizo interrumpida por huecos rasgados en cada una de las plantas, rotos por los pilares de la estructura metálica del edificio en las plantas baja y primera, y cubiertos con ventanas continuas. Esta solución es común a buen número de proyectos de su autoría, tales como el monasterio de Santa Inés o los colegios de San Martín de Porres y el de Nuestra Señora de la Paz. En el lugar en que se produce el quiebro de la fachada el colegiado proyectó una pantalla vertical de hormigón que tapa el hueco de escalera y permite la entrada de luz lateralmente ${ }^{38}$. Con esta solución el padre Coello rompió la continuidad de la fachada, que habría resultado excesiva al ocupar la totalidad del frente de la calle, y cuya estrechez habría destacado más si cabe este efecto. Por su parte, la fachada interior repite la solución de la principal, aunque prescinde del zócalo de hormigón, sustituido en el proyecto originario en las plantas baja, primera y segunda por ventanales, si bien permanecía transformado

\footnotetext{
${ }^{33}$ AHPZa, DPV, 70/24, Memoria, 2.

4 AHPZa, DPV, 70/24, Memoria, 3.

${ }^{5}$ AHPZa, DPV, 70/24, Memoria, 4.

${ }^{36}$ AHPZa, DPV, 70/24, Memoria, 4.

${ }^{37}$ AHPZa, DPV, 70/24, Memoria, 5.

38 AHPZa, DPV, 70/24, Memoria, 5.
} 
en antepecho en las dos últimas ${ }^{39}$. Esta respuesta ha sido repetida en numerosos proyectos, de entre los que destaca el colegio de los Sagrados Corazones de Torrelavega ${ }^{40}$. Por su parte, la fachada a la calle Candelaria Ruiz del Árbol ponía de relieve dos volúmenes aparentemente conectados por una discreta puerta adintelada. El proyecto denotaba así el bloque del colegio propiamente dicho y el del cuerpo de salón de actos y capilla, este último casi concebido a modo de apéndice del primero. Realizada en ladrillo del mismo color pajizo sobre un escueto zócalo de hormigón que disimulaba la ligera pendiente, el primero de los volúmenes aparecía como testero lateral ciego y totalmente liso, a excepción de una gran cruz metálica que además servía como campanario. El módulo correspondiente a la capilla, igualmente liso y ciego, ponderaba la pendiente de la cubierta del templo ${ }^{41}$.

No obstante lo proyectado, los planos que resultaron definitivos, fruto de un modificado del proyecto, introdujeron una serie de cambios sobre la propuesta originaria que alteraron la solución final del centro. Éstos prescindieron de una de las plantas previstas, lo cual redujo la altura del inmueble a tres plantas sobre semisótano más ático. También se sustituyó la cubierta plana por un tejado a dos aguas. El arquitecto disminuyó la longitud del bloque principal, al perder hasta un metro y medio para incrementar la anchura de la calle Candelaria Ruiz del Árbol en su conexión con la calle La Reina ${ }^{42}$. Igualmente el padre Coello hubo de modificar el alzado Sur del inmueble para adecuarse a las condiciones edificatorias del casco antiguo, cambiando el material elegido y la propia silueta del conjunto. (Figuras 3 y 4). La nueva solución dio lugar a una fachada realizada en mampostería de piedra sobre zócalo de placas de granito, a excepción de las esquinas, los recercos de la puerta de acceso a la capilla desde el exterior -resuelta en arco de medio punto-, la hornacina superpuesta a ésta y la culminación del colegio, que fueron efectuados en sillares de ese material, adoptando cierto diálogo entre tradición y modernidad. El alzado del bloque destinado a colegio y residencia se convirtió en una suerte de campanario, pues el arquitecto ideó tres huecos para campanas -en los primeros dibujos adintelados pero finalmente ejecutados formando arco de medio punto- que aún permanecen vacios, mientras que una cruz realizada con perfiles metálicos sobresale y corona el inmueble ${ }^{43}$.

${ }^{39}$ Con la modificación del proyecto esta solución se repitió únicamente en la planta primera, al ser eliminada una de las inicialmente proyectadas.

${ }^{40}$ Iturgaiz Ciriza, 2001: 89-97. Hernández Martín, 2004: 64. Gago Vaquero, 1997: 192. Ávila de la Torre, 2011: 207.

${ }^{41}$ AHPZa, DPV, 70/24, Plano 13.

${ }^{42}$ AMZa, OyU, OM/795/66, Plano de fachada a la calle La Reina. El expediente contiene 11 planos del proyecto modificado, que resultó definitivo, algunos de ellos repetidos.

43 AMZa, OyU, OM/795/66, Plano de alzado a la calle Candelaria Ruiz del Árbol. Firmado en diciembre de 1967, recoge los vanos adintelados, mientras que el rubricado en 
Esta solución ciertamente contrasta con el planteamiento y diseño originales netamente racionalistas, y aún con el resultado del conjunto.

\section{LA CAPILLA, ESPACIO SINGULAR}

El colegio adopta para uso docente y residencial un volumen de marcado carácter longitudinal, mientras que una segunda pieza, más hermética, corresponde al salón de actos y a la capilla superpuestos, el primero completamente enterrado. Esta composición, repetida en el colegio cántabro aludido, entre otros, genera un núcleo que se establece como elemento independiente y relativamente aislado pero en contacto con el resto del inmueble, al que se une por los pies. Condicionada por la exigencia de preservar la vinculación histórica con los orígenes de la orden en la capilla de La Candelaria, el arquitecto mantuvo su ubicación invariable, aunque girada 180 grados respecto de su orientación original, con el fin de dar más altura al presbiterio y que este ámbito ganase en importancia ${ }^{44}$. Adoptó una planta trapezoidal, impuesta por la irregularidad de la finca pero también por condicionantes relativos a la composición, solución que el arquitecto ya había ensayado en la capilla del seminario de La Virgen del Camino y que repitió en otros proyectos ${ }^{45}$. En el extremo situado a poniente el colegiado ubicó el presbiterio, y a los pies diseñó un doble acceso en ángulo desde el colegio y otro más en el alzado lateral de la calle Candelaria Ruiz del Árbol. (Figura 5). En la versión final también dispuso un acceso desde el patio y junto al presbiterio.

El presbiterio tiene forma de trapecio, ocupa íntegramente el ancho de la sala y se eleva tres niveles, aunque originalmente fueron cuatro los proyectados a tenor del plano de sección, el primero de una huella doblemente ancha que las restantes $^{46}$. En los primeros planos el arquitecto consignó únicamente el altar, también diseñado por él, ubicado en el centro del espacio y elevado sobre una estructura de madera rectangular que ocupaba la mitad de la longitud del presbiterio, y que definitivamente se extendió hasta alcanzar prácticamente la grada ${ }^{47}$. En este movimiento apreciamos la adopción en el proyecto de los postulados litúrgicos del Concilio Vaticano II, precisamente cuando este sínodo estaba en pleno desarro1lo. En efecto, la propuesta inicialmente trazada con el altar situado muy próximo al testero, aunque no adosado a él, dio paso a su acercamiento a la asamblea y con ello a la creación de un espacio que permitiera la celebración del sacerdote

enero de 1968 ya los muestra formado arco de medio punto. Archivo Estudio Fray Coello de Portugal. (AEFCP), Tubo 13, Plano 12, enero 1968.

${ }^{44}$ AHPZa, DPV, 70/24, Memoria, 4.

${ }^{45}$ Iturgaiz Ciriza, 2001: 67.

46 AHPZa, DPV, 70/24, Plano 13.

${ }^{47}$ AHPZa, DPV, 70/24, Plano 4. Compárese con la propuesta planteada en AEFCP, Tubo 13, Plano s/n, "presbiterio y altar", fechado en junio de 1969. 
de cara a los fieles. Por otro lado, en los planos definitivos el arquitecto dispuso también la sede de forma cúbica en el eje del espacio y muy próxima al muro, así como una repisa insertada en el centro del testero y sobre la que se apoyaba el sagrario, concebido como una caja prismática, y su lamparilla ${ }^{48}$. Ambos elementos se previeron en consonancia con el estilo y material del altar. No obstante, a pesar de estas propuestas, la ejecución definitiva difirió sensiblemente de lo previsto y el colegiado prescindió de estos últimos elementos. El altar se ejecutó formado por una losa de mármol negro pulido de 1,90 por $0,90 \mathrm{~m}$, apoyada sobre un prisma cuadrangular de $0,70 \mathrm{~m}$ de altura y realizado en el mismo material pero picado. También es de mármol negro una pequeña lámina insertada en el testero utilizada como credencia.

La concepción de la nave determina la direccionalidad del espacio litúrgico, acentuada por la disposición de los bancos en forma de batallón hacia el altar con pasillo central y acceso también por los laterales. De alguna manera se refleja aún cierta tendencia hacia la convergencia de muros, lo que constituyó un hito en el espíritu preconciliar. Esa aportación inicialmente realizada en la arquitectura religiosa contemporánea en nuestro país por Miguel Fisac en el convento dominico vallisoletano de Arcas Reales en 1952 alcanzó tal impacto que mereció una de las sesiones de crítica de la Revista Nacional de Arquitectura ${ }^{49}$, prodigándose en 1953 entre autores como Carlos Arniches en la iglesia del poblado cordobés de Algallarín ${ }^{50}$ y por Alejandro de la Sota en el sevillano de Esquivel ${ }^{51}$. No obstante el arcaísmo de estas propuestas resultaba superado en esta capilla. Por otro lado, al tratarse de un templo destinado a capilla de un colegio e internado y, paralelamente, lugar de culto de la comunidad de religiosas, carece de baptisterio, coro e incluso otras dependencias propias del uso parroquial. Tampoco fue diseñado un espacio propio para la reserva y oración ante el Santísimo, puesto que, como veremos a continuación, el sagrario finalmente se incorporó al retablo colocado en el testero. Sin embargo, el hecho de que esta pieza se encuentre desplazada respecto del eje del presbiterio parece sugerir una suerte de ámbito específico para esta función en la parte derecha de la nave. A pesar de la ausencia de algunos espacios propios para la celebración de ciertos sacramentos o emplazamientos para el desempeño de algunos ministerios, el padre Coello sí diseñó un espacio reservado para el sacramento de la reconciliación penitencial, al empotrar un confesonario a los pies de la nave entre los accesos interior y exterior a la capilla. Realizado en madera, posee una sede para el confesor y dos espacios laterales para los penitentes, cerrados con puertas para garantizar la discreción y el sigilo sacramental. Sus líneas rectas y la ausencia de decoración en las puertas

\footnotetext{
48 AEFCP, Tubo 13, Plano s/n, "presbiterio y altar" y Plano s/n, "sección del presbiterio".

49 Anónimo, 1955: 10-19.

${ }^{50}$ Rabasco, 2017: 166-180.

${ }^{51}$ Fernández-Cobián, 2055: 206, 208-210 y 272-273.
} 
contribuyen a que pase desapercibido. La sacristía, colindante con este espacio y ubicada a los pies de la capilla, posee una puerta de ingreso yuxtapuesta al confesonario y formando una unidad con este.

El techo de la capilla ostenta especial singularidad al remarcar el ritmo ascensional del espacio partiendo desde los pies hasta el presbiterio. Si nos atenemos a los planos del proyecto inicial, firmado en julio de 1964, el techo de la capilla partía de la altura de $3 \mathrm{~m}$ existente entre forjado y forjado de la planta baja para comenzar a crecer de forma progresiva en el punto de mayor anchura de la nave, culminando exactamente en la vertical del altar, donde un torrente de luz descendía sobre el presbiterio. El empleo de una lámina formada por listones de madera reforzaba la continuidad ascensional del espacio ${ }^{52}$. El padre Coello concedió especial relevancia a esta solución, hasta tal punto que la única alusión que hace de la capilla en la memoria del proyecto es, precisamente, para remarcar este efecto ${ }^{53}$. A pesar de ello, la solución definitiva, elaborada casi cinco años más tarde, alteró levemente esta solución. Mantenida la altura entre forjados, en el punto de máxima anchura de la nave el arquitecto insertó un ventanal continuo perpendicular al plano del suelo y de $0,90 \mathrm{~m}$ de altura que permitía la iluminación natu$\mathrm{ral}^{54}$. Desde la parte superior de esta luminaria arranca un nuevo tramo de techo, ahora con pendiente ascendente, que culmina en un segundo ventanal ubicado exactamente sobre el presbiterio y que repite la solución, convirtiéndose en un auténtico derroche de luz que se vierte sobre el altar. De este modo el colegiado secuenció el ritmo ascensional del techo en dos tramos partiendo desde la horizontal.

Especial cuidado puso el arquitecto en la elección de los materiales pues, sin ser singularmente valiosos, contribuyeron a reforzar el criterio primordial de expresividad y nobleza pero sin hacer ostentación ${ }^{55}$. A ello contribuyó también la austeridad cromática empleada por el arquitecto. Al pavimento de baldosas de terrazo verde oscuro de la nave y de mármol de Sierra Elvira de color gris del presbiterio $^{56}$, además del negro del altar y las pilas de agua bendita, se contrapone el blanco masivamente empleado en los paramentos y en las placas de escayola del techo. Únicamente interrumpe esta dualidad el color marrón de la madera del retablo y la empleada parciamente en el suelo del presbiterio, así como el tono ámbar de las cristaleras que permiten la entrada de luz y el bronce y óxido del sagrario. Junto a este criterio de austeridad, la concepción del espacio determina el estilo del templo. La limpieza de volúmenes y la linealidad de sus formas caracterizan la amplitud de los espacios, los cuales consiguen la plena visibilidad. Así, sobre la planta discurre un haz de convergencias impulsado hacia el presbiterio

\footnotetext{
${ }^{52}$ AHPZa, DPV, 70/24, Plano 13.

${ }^{53}$ AHPZa, DPV, 70/24, Memoria, 4.

${ }^{54}$ AEFCP, Tubo 13, Plano s/n, "sección del presbiterio".

55 Fernández-Cobián, 2001: 37.

${ }^{56}$ AEFCP, Tubo 13, Plano s/n, junio 1969.
} 
que concentra la atención sobre el altar. El carácter sacro del espacio no viene dado por el empleo de símbolos o la decoración, sino porque ha sido concebido como tal desde el criterio de máximo despojamiento ${ }^{57}$. Todos estos elementos se engranan en esta capilla mediante la luz, elemento de singular importancia conseguido mediante el ritmo ascensional del techo. La penumbra, que protagoniza el espacio y proporciona un ambiente acogedor, queda contrarrestada por la iluminación rasante que se desliza por las paredes laterales, el techo y el presbiterio, generando una atmósfera de espacio ingrávido ${ }^{58}$. El torrente de luz que desciende precisamente sobre el presbiterio contribuye a significar el ámbito de mayor sacralidad del recinto. (Figura 6).

Como en la mayoría de sus creaciones, Coello de Portugal buscó materializar lo útil, lo necesario y lo funcional, renunciando a la ostentación ${ }^{59}$. No ideó decoración alguna para esta capilla, pretendiendo seguramente que el espacio mismo y la austeridad fuesen el criterio estético primordial. La solución concreta del edificio evidencia el debate que se estaba produciendo en nuestro país sobre la renovación de la arquitectura religiosa contemporánea precisamente en el momento en que Francisco Coello firmaba este proyecto. La orden dominica, a la que pertenecía, asumía entonces la vanguardia en esta puesta al día de la arquitectura y las bellas artes al servicio de la arquitectura creada para la liturgia, y la revista ARA con especial protagonismo capitaneaba este cambio precisamente desde 1964. Exactamente en sus primeros once números la publicación desarrolló una revisión conceptual de los principios teóricos y funcionales relativos al templo contemporáneo, abundando progresivamente en la renovación operada en la arquitectura religiosa posconciliar, a la que animaba con denodado ánimo ${ }^{60}$. Los debates que abría el Movimiento de Arte Sacro, y la propia revista como su órgano de difusión, encontraron reflejo en la concepción y formas que el propio Coello había introducido en esta capilla, tales como el funcionalismo sacro, la cuestión del sagrario, la esencialidad, sinceridad y pobreza, la artificiosidad y la depuración lingüística, entre otros ${ }^{61}$.

Como fue una constante en el resto de sus obras, Coello de Portugal diseñó también el mobiliario litúrgico de la capilla, reconociendo en estos elementos la única y auténtica decoración necesaria, seguramente con la intención de que la renovación de las artes afectase a todos los aspectos de forma integral. Como ya dijimos, quedó excluida la sede y el ambón, pero salieron de su pluma el altar y las dos pilas de agua bendita, de marcada ortogonalidad. No obstante, Coello dio

\footnotetext{
${ }^{57}$ Fernández-Cobián, 2001: 34-35.

${ }^{58}$ Iturgaiz Ciriza, 2001: 67-68.

${ }^{59}$ Iturgaiz Ciriza, 2001: 63.

${ }^{60}$ Fernández-Cobián, 2055: 157-158.

${ }^{61}$ Números 1 a 11 de la revista $A R A$ correspondientes a los años 1964 a 1967 y Gar-
} cía Crespo, 2015: 21 ss. 
también espacio a la incorporación de obra de otros artistas, logrando un conjunto plenamente articulado, quizá porque asumieron los mismos criterios estéticos, litúrgicos y decorativos. La integración de las artes se ciñó principalmente al presbiterio, cuyo resultado fue fruto de la colaboración entre el arquitecto y el escultor Tomás Crespo Rivera. Propuesto al colegiado por el propietario de la empresa encargada de la realización de la carpintería de la obra, Fermín Crespo, por ser hermano suyo, gozó de absoluta libertad de concepción y ejecución de los trabajos $^{62}$. Ante la ausencia de retablo, Crespo Rivera ideó la colocación de un perfil metálico en forma de cruz apoyado directamente en el testero, ocupando íntegramente la altura del muro y ligeramente ladeado hacia la izquierda respecto del eje del espacio. Sobre esta estructura colocó el crucificado gótico que se hallaba en el coro de la capilla de La Candelaria y que era especialmente importante para la fundadora de la orden. Con esta sencilla estructura potenció los valores estéticos de la imagen. Simétrico a la disposición del Cristo el artista diseñó un relieve-mural de carácter constructivo realizado en madera de ukola formado por dieciséis piezas que, sin firmar, fue terminado e instalado en 1970 para la inauguración del colegio. Representa simbólicamente al Espíritu Santo, las imágenes de la Sagrada Familia y motivos abstractos de carácter central y radial, todos ellos emergiendo de una estructura arbórea tallada en el cuarto inferior. En la parte superior, una esquemática ave representa la tercera persona de la Santísima Trinidad. San José en el taller y el Niño portando un martillo con su mano derecha y una flor con la izquierda aparecen en pie y de cuerpo entero, caracterizados por un marcado frontalismo, repetido en la imagen de María, que aparece asomada a una ventana con los brazos cruzados ${ }^{63}$. (Figura 7).

El panel, de 1,60 m de ancho, ocupa la totalidad de la altura del testero y funciona como retablo que custodia el sagrario. Éste tiene forma de caja prismática rectangular, está fundido en bronce a la arena y se encuentra empotrado directamente en el relieve. Diseñado también por Crespo Rivera siguiendo el mismo cuño constructivo, tiene una única puerta que se abre en el centro del frontal y que está decorada con un motivo abstracto central plenamente acorde con los del retablo. La frase "El que me come vive en mi" $(\mathrm{Jn} 6,56)$ aparece grabada en caracteres mayúsculos. El tallista Miguel Pérez Corredera ejecutó el ambón ${ }^{64}$, realizado en madera de sapely sobre estructura de metal, diseñado con motivos basados

${ }^{62}$ Información aportada por Tomás Crespo Rivera en una entrevista mantenida el 16 de octubre de 2012 durante una visita conjunta a la capilla. Esta circunstancia fue confirmada por el propio arquitecto en una entrevista realizada el 26 de diciembre de 2012.

${ }^{63}$ El artista utilizó como modelo para tallar el niño Jesús a su sobrina Teresa Crespo García.

${ }^{64}$ El artista no ha sido capaz de precisar la fecha exacta de realización, aunque la limita entre 1970 y 1992. Información aportada por el hijo del artista en una entrevista celebrada el 2 de noviembre de 2012. 
en los del retablo y de marcado carácter mobiliar, a pesar de que las directrices del Vaticano II insistieran en su condición como lugar. Esta circunstancia se repitió con la sede litúrgica, inexistente en el proyecto original y cuyas veces hace un sillón frailero. El 13 de octubre de 2003 fue colocada en el lateral derecho del presbiterio una escultura en bronce titulada "Alegría y esperanza", obra de la religiosa de esta congregación Pilar de la Fuente Navarro. Representa a Santa Bonifacia Rodríguez de Castro, fundadora de las Siervas de San José, en pie y con las manos a la espalda, en actitud orante, caracterizada por unos rasgos físicos suaves y por su tamaño próximo al natural ${ }^{65}$.

Definitivamente, la capilla como unidad en sí misma refleja una solución arquitectónica compacta y un modelo sacro repetido por Coello en otras propuestas de su autoría, como el madrileño Centro Experimental de Promoción Social, precisamente coetáneo de este zamorano. Estas soluciones primeras, más contenidas y racionales, esencialmente prismáticas, puras y elementales, muestran el binomio modernidad/tradición de los edificios sacros de la década de los sesenta, concretamente el que nos ocupa poniendo el acento en el empleo del lenguaje vanguardista y el protagonismo de la luz, aunque manteniendo aún el esquema direccional en la concepción del espacio litúrgico ${ }^{66}$. Coello fue evolucionando hacia modelos caracterizados por cubiertas de bóvedas alabeadas más constructivistas y próximas a soluciones escultóricas, tales como las capillas de los colegios Nuestra Señora de la Paz, Nuestra Señora del Yermo o Santa Rosa de Lima, o iglesias como Nuestra Señora del Valle.

Además de la capilla, el padre Coello proyectó en el colegio otro espacio religioso, aunque finalmente no llegó a albergar este uso y nunca fue considerado como tal. El propio arquitecto lo denominó "capilla" en los planos y "oratorio" en la memoria. Se encontraba en la planta baja del colegio, exactamente ubicado frente a los pies de la capilla del centro, formando parte de las habitaciones que daban a la fachada principal del inmueble. Este espacio había surgido en el proyecto de julio de 1964 como consecuencia del condicionante impuesto de preservación del lugar donde habían aparecido los documentos fundacionales de la orden. El arquitecto se vio en la necesidad de mantener este espacio, pero, por otro lado, como ya hemos indicado, diseñó la capilla alterando 180 grados su orientación con el fin de destacar el presbiterio. Para salvar la exigencia de la congregación, el colegiado decidió crear este oratorio con el fin de salvaguardar dignamente el lugar de aparición de los documentos citados ${ }^{67}$. La única información que poseemos de las características de este oratorio nos las aporta el plano de planta del colegio, en el que Francisco Coello proyectó una sala de forma

${ }^{65}$ Información aportada por Pilar de la Fuente Navarro, autora de la obra, en una entrevista mantenida el 13 de octubre de 2012.

${ }^{66}$ Delgado Orusco, 2009: 327-328.

${ }^{67}$ AHPZa, DPV, 70/24, Memoria, 4. 
rectangular, dotada con una puerta de acceso en el extremo Norte del lado mayor. El otro lado mayor de la sala, coincidente con la fachada del inmueble, poseía un ventanal elevado en la totalidad de su longitud. La dependencia cumple actualmente la misión de señalar el lugar de aparición de aquellos importantes escritos, además de custodiar y exponer como museo otros recuerdos de la orden, pero desposeída de una condición sagrada que nunca llegó a tener.

\section{EL PROCESO DE EJECUCIÓN}

Una vez redactado el proyecto dio comienzo el proceso de construcción del edificio. El centro fue declarado de Interés Social por el Ministerio de Educación Nacional, lo cual favoreció también económicamente la ejecución de esta obra ${ }^{68}$. El 11 de junio de 1966 la comisión municipal permanente autorizó la construcción del inmueble ${ }^{69}$, y el 4 de julio siguiente el proyecto contó con el plácet del delegado provincial del Ministerio de la Vivienda ${ }^{70}$. Sin embargo, el Ayuntamiento de la capital terminó por no aceptar la propuesta presentada. Una vez iniciadas las obras, llevadas a cabo por la empresa Cindosa y bajo la responsabilidad del aparejador Amador Fernández Álvarez y otro técnico local ${ }^{71}$, la comisión municipal permanente celebrada el 26 de julio de 1967 acordó remitir el proyecto a la Dirección General de Bellas Artes en razón de la peculiar ubicación del nuevo centro dentro del casco histórico-artístico de la ciudad ${ }^{72}$. El alcalde mandó paralizar los trabajos el 9 de septiembre siguiente ${ }^{73}$, mientras que tres días después el arquitecto municipal emitió un informe en el que dispuso que se construyeran muros de contención para evitar desprendimientos en las calles La Reina y Candelaria Ruiz del Árbol ${ }^{74}$.

A pesar de que el padre Coello se sometió plenamente a las condiciones prescritas por la oficina técnica de obras de la corporación local, que exigía mantener exactamente el trazado de los muros de las viejas casas, como ya estudiamos se desestimó la solución presentada por el arquitecto exigiéndole el retranqueo del inmueble hasta un metro y medio en la esquina formada por las calles La Reina y Candelaria Ruiz del Árbol con el fin de facilitar la salida y

${ }^{68}$ AMZa, OyU, OM/615/68, Expediente administrativo. Solicitud de autorización de obras, de 24 de junio de 1966.

${ }^{69} \mathrm{AMZa}, \mathrm{OyU}, \mathrm{OM} / 615 / 68$, Expediente administrativo.

${ }^{70}$ AHPZa, DPV, 70/24, Documentación administrativa.

${ }^{71} \mathrm{AMZa}, \mathrm{OyU}, \mathrm{OM} / 615 / 68$, Expediente administrativo. Solicitud de autorización de obras, de 24 de junio de 1966.

${ }^{72} \mathrm{AMZa}, \mathrm{OyU}, \mathrm{OM} / 615 / 68$, Expediente administrativo. Solicitud de autorización de obras, de 24 de junio de 1966.

${ }^{73}$ AMZa, OyU, OM/615/68, Oficio de 9 de septiembre de 1967.

${ }^{74}$ AMZa, OyU, OM/615/68, Informe de 12 de septiembre de 1967. 
estacionamiento de camiones en los bajos del edificio que se encontraba frente al colegio en la primera de las calles ${ }^{75}$. La oficina de servicios técnicos de la Dirección General de Bellas Artes emitió un informe en el que se exigió la inclusión de modificaciones referentes al volumen y carácter del inmueble y a la proximidad con tres edificios de relevancia histórico-artística, comunicado a los interesados el 25 de septiembre de $1967^{76}$. A partir de este punto, con la exigencia de adecuar el edificio al contexto monumental, el arquitecto ideó la definitiva solución determinada por la reducción de una planta, la modificación de la cubierta, el retranqueo del edificio y la modificación integral del alzado Sureste empleando aparejo de piedra e introduciendo ciertos elementos historicistas ${ }^{77}$. El colegiado rubricó los planos definitivos entre enero de 1968 y junio de $1969^{78}$. El 27 de octubre de 1967 el alcalde reiteró la paralización de las obras por no haberse hecho efectivas ${ }^{79}$, ante lo cual la superiora de la comunidad, Francisca Sánchez Barba, solicitó el 27 de diciembre siguiente la continuación de las mismas al contar con la notificación de la aprobación del proyecto reformado por parte de la Dirección General de Bellas Artes, cuestión que se hizo efectiva en la

${ }^{75}$ Información aportada por el padre Francisco Coello de Portugal y Acuña en una entrevista celebrada el 15 de octubre de 2012. El arquitecto manifestaba en esta conversación su disconformidad con la solución exigida, argumentando que la medida fue del todo arbitraria y fundamentada en razones de amistad entre el alcalde de la capital y el propietario del inmueble vecino.

${ }^{76}$ AMZa, OyU, OM/615/68, Expediente administrativo, Oficio del director general de Bellas Artes, de 25 de septiembre de 1967.

77 AEFCP, Plano 12 digitalizado, "Fachada de la iglesia", fechado en enero de 1968.

${ }^{78}$ AEFCP, Plano 12 digitalizado y Tubo 13, Plano s/n, "presbiterio y altar", fechado en junio de 1969. También existe un plano realizado en papel cebolla que contempla la disposición de los bancos en la iglesia, fechado en agosto de 1969. Tras un proceso dilatado en el tiempo y concienzudo de búsqueda de la memoria correspondiente a los planos definitivos -en caso de haberla- el resultado del mismo fue insatisfactorio. La tarde del 26 de diciembre de 2012 rastreamos los archivos conservados en los sótanos del convento de Santo Domingo el Real ubicado en la calle Claudio Coello número 141 de Madrid donde el padre Coello de Portugal conservaba sus antiguos proyectos, así como las carpetas y tubos depositados en el propio estudio donde el arquitecto custodiaba la documentación referente a los mismos. En ningún caso apareció más material referido al edificio que estudiamos que los planos ya aludidos. Ante esta circunstancia, el propio padre Coello acabó apuntando que probablemente no existiera tal memoria, y que seguramente en aquel momento realizó las modificaciones oportunas en la planimetría pero sin presentar una nueva redacción de ésta, pues la firmada en julio de 1964 sería suficiente para justificar los trabajos. Aportamos estos datos frente a la afirmación mantenida por José Luis Gago Vaquero en la que manifiesta que la propuesta definitivamente ejecutada está datada en 1968, sin precisar más datos ni fuentes donde fundamentar esa aseveración. Gago Vaquero, 1997: 198.

${ }^{79}$ AMZa, OyU, OM/615/68, Expediente administrativo, Oficio de 27 de octubre de 1967. 
sesión de la comisión municipal permanente de 29 de diciembre ${ }^{80}$. Finalmente, el 10 de enero de 1968 el director general de Bellas Artes notificó a la alcaldía la aprobación definitiva del proyecto ${ }^{81}$.

Finalizadas las obras, las religiosas y alumnas internas se establecieron definitivamente en el nuevo inmueble, provenientes de la casa ubicada en la calle Ramos Carrión número 59 que les había prestado el obispado mientras duró la construcción, y que había sido Casa Social de Acción Católica y anteriormente colegio de La Purísima Concepción. El 10 de marzo de 1970 el canónigo prefecto de ceremonias examinó la capilla del colegio para informar sobre la conformidad para su erección, indicando que el oratorio no estaba provisto aún de la sede y ambón litúrgicos, así como tampoco estaba instalado el sagrario ${ }^{82}$. El día siguiente, 11 de marzo de 1970, el vicario general de la diócesis, en sede vacante, David de las Heras, erigió canónicamente como oratorio semipúblico la capilla del colegio para uso de la comunidad y de las alumnas internas, autorizando asimismo a bendecir este espacio para el culto al capellán de la comunidad ${ }^{83}$, inaugurándose el día de San José.

\section{NUEVAS INTERVENCIONES DEL PADRE COELLO}

El padre Coello recibió un nuevo encargo de las Siervas de San José para llevar a cabo la ampliación del centro mediante la construcción de un inmueble en la calle Orejones integrado por piscina, construcciones auxiliares y vivienda para el empleado de la granja del colegio, presentando su propuesta firmada en marzo de $1968^{84}$. (Figura 8). Tras sufrir una serie de modificaciones, la propuesta fue aprobada por la comisión municipal en la sesión de 23 de septiembre de $1968^{85}$. Posteriormente, el arquitecto local Alfonso Crespo Gutiérrez redactó en enero de 1976 la ampliación del colegio en la calle Orejones con la construcción de un gimnasio, propuesta que tuvo que modificar en mayo siguiente para contextualizarlo con el entorno edificado ${ }^{86}$. En junio de 1982 los arquitectos Lucas Espinosa Navarro y Alberto Jiménez Cesteros redactaron un proyecto para la ampliación del centro con la construcción de un nuevo edificio en la calle Orejones ${ }^{87}$, y once años más

${ }^{80} \mathrm{AMZa}, \mathrm{OyU}, \mathrm{OM} / 615 / 68$, Expediente administrativo, Diligencia a la carta de 27 de diciembre de 1967.

${ }^{81}$ AMZa, OyU, OM/615/68, Expediente administrativo, Oficio, de 10 de enero de 1968.

${ }^{82}$ Véase también ADZa, Curia, 1970, D. 2.

${ }^{83}$ ADZa, Curia, 1970, D. 2. Véase también Archivo Comunidad Siervas de San José, Documentos del obispado, Oficio sin clasificar, de 11 de marzo de 1970.

${ }^{84}$ AHPZa, DPV, 95/02.

${ }^{85}$ AMZa, OyU, OM/615/68.

${ }^{86}$ AHPZa, DPV, 235/03 y AMZa, OyU, OM/196/76.

${ }^{87}$ AMZa, OyU, OM/154/82. 
tarde se efectuó el derribo de los inmuebles números 1 y 3 de la misma calle para una nueva ampliación de las dependencias ${ }^{88}$. La progresiva ejecución de estos proyectos consiguió ampliar el espacio del centro.

Con el comienzo del siglo XXI Coello de Portugal y Acuña volvió a intervenir en el centro para realizar una nueva ampliación. La que fuera casa del doctor Valbuena, colindante por la calle La Reina, fue adquirida por las religiosas, derribada e incorporada según un proyecto rubricado en enero de $2002^{89}$, sometido catorce meses después a una versión reformada ${ }^{90}$, y en marzo de 2009 a un segundo reformado ${ }^{91}$. También el padre Coello redactó un proyecto de reforma interior y ampliación de huecos en las fachadas del colegio en julio de $2003^{92}$, mediante el cual las religiosas requirieron al arquitecto la incorporación de dos nuevos oratorios en las dependencias del centro. El primero de ellos, ubicado en el extremo Norte del ático, tiene planta poligonal tendente al rectángulo e incorporó un retablo con elementos procedentes del antiguo colegio Patrocinio de San José de Madrid realizado por José Antonio Pérez González y Miguel Pérez Corredera en $2006^{93}$, así como la estructura portante del sagrario realizada en 2007 por el primero y cuatro vidrieras de hormigón con motivos cósmicos y relativos a la naturaleza obra de Luis Quico ${ }^{94}$. La segunda capilla, ubicada en el extremo Sur de la segunda planta ${ }^{95}$, tiene planta trapezoidal muy próxima al rectángulo ${ }^{96}$ e incorpora dos imágenes y sagrario seriados, así como siete vidrieras con motivos cósmicos y de la naturaleza realizadas por Luis Quico, además de un crucifijo de hierro forjado realizado por José María Subirachs procedente de la casa de madres mayores de Salamanca ${ }^{97}$.

\section{CONCLUSIONES A MODO DE RECAPITULACIÓN}

El alcance de esta arquitectura en el conjunto de la creación de Francisco Coello de Portugal debemos ponderarlo necesariamente vinculado al momento

${ }^{88}$ AMZa, OyU, OM/271/93.

${ }^{89} \mathrm{AMZa}, \mathrm{OyU}, \mathrm{OM} / 375 / 02$ y OM/50/03.

${ }^{90}$ AMZa, OyU, OM/219/03.

${ }_{91}$ AMZa, OyU, OM/70/09.

${ }_{92}$ AMZa. OyU. OM/420/03.

${ }^{93} \mathrm{La}$ estructura fue realizada en madera por los tallistas locales José Antonio Pérez González y su padre Miguel Pérez Corredera. Información aportada por ambos en una entrevista celebrada el 24 de octubre de 2012.

${ }^{94}$ AMZa, OyU, OM/420/03, Plano de plantas, ático.

95 AMZa, OyU, OM/420/03, Plano de plantas, planta segunda.

${ }_{96}$ AEFCP, Carpeta 162/3, Plano capilla en planta segunda.

${ }^{97}$ Información aportada por Manuela Miguel Gallego en una entrevista celebrada el 24 de septiembre de 2012. 
en que fue proyectado, precisamente por ser ésta su sexta obra en un total de tres centenares. A pesar de tratarse de sus primeros diseños, adopta ya una fuerte personalidad al adherirse sin miramientos a los criterios que a la larga resultarán esenciales y característicos en su arquitecto como la superación de los moldes tradicionales hacia la introducción del protagonismo de la luz, la pureza de líneas y la sobriedad espacial, el tratamiento de los materiales y la integración de las partes del todo unitario del espacio sagrado, amén de la característica descontextualización del edificio en su conjunto. Paralelamente, en el panorama de la arquitectura religiosa contemporánea española el conjunto de la obra de Coello será precisamente uno de los acicates más determinantes para su renovación lingüística, aportando esta propuesta zamorana la consolidación del nuevo modelo ya en plena década de los 60 .

Fecha de recepción: 30 de octubre de 2020.

Fecha de aceptación: 2 de mayo de 2021.

\section{BIBLIOGRAFÍA}

Anónimo (1955): "Sesión de crítica de arquitectura dedicada a la iglesia de los PP. Dominicos de Valladolid”. En: Revista Nacional de Arquitectura, 157, pp. 10-19.

Ávila de la Torre, Álvaro (2011): "En la ciudad de Zamora durante los siglos XIX y XX”. En: López Moro, Francisco Javier/López Plaza, Miguel/Vasallo Toranzo, Luis/Azofra Agustín, Eduardo/García de los Ríos, José Ignacio: De los plutones a los monumentos: Un recorrido temático por la piedra del este de Sayago (Zamora). Zamora: Instituto de Estudios Zamoranos Florián de Ocampo, pp. 193-213.

Coello de Portugal, Francisco (2005): Fray Coello de Portugal. La arquitectura, un espacio para el hombre. Pamplona: Escuela Técnica Superior de Arquitectura de la Universidad de Navarra.

De Cáceres Sevilla, Adela (1981): Encina y piedra. Madre Bonifacia Rodríguez de Castro. Fundadora de la Congregación de Siervas de San José. Salamanca: Siervas de San José.

Delgado Orusco, Eduardo (2006): Entre el cielo y el suelo. Arte y arquitectura sacra en España, 1939-1975. Madrid: Fundación SEK.

Fernández Cobián, Esteban (2005): El espacio sagrado en la arquitectura española contemporánea. Santiago de Compostela: COAG.

- (2001): “El despojamiento como deber”. En: Fernández-Cobián, Esteban (coord.): Fray Coello de Portugal, dominico y arquitecto. Madrid: Fundación Antonio Camuñas-San Esteban, pp. 19-41.

Gago Vaquero, José Luis (1997): Enrique Crespo y la modernidad. Zamora, siglo $X X$. Zamora: Ayuntamiento de Zamora. 
García Crespo, Elena (2015): Los altares de la renovación. Arte, arquitectura y liturgia en la revista ARA (1964-1981). Salamanca: San Esteban.

García-Lozano, Rafael Ángel (2010): "El hospital y la capilla de la Cofradía de los Ciento. Aportaciones para el estudio del urbanismo y la arquitectura de Zamora". En: Studia Zamorensia, 9, pp. 35-86.

- (2012): "La obra benéfico-docente de la Compañía de Jesús. El colegio menor San Alfonso Rodríguez". En: Miscelánea Comillas. Revista de Ciencias Humanas y Sociales, 70, pp. 225-240.

Gómez Carabias, Faustino (1884): Guía sinóptica, estadístico-geográfica de las poblaciones y parroquias de la Diócesis de Zamora y vicarías de Alba y Aliste. Zamora: Imprenta y litografía de J. Gutiérrez.

Hernández Fuentes, Miguel Ángel/Mateos Carretero, Pilar (2005): Bonifacia en Zamora. Un recorrido por la ciudad siguiendo las huellas de una santa. Zamora: Ayuntamiento de Zamora.

Hernández Martín, Joaquín (2004): Guía de Arquitectura de Zamora. Desde los orígenes al siglo XXI. Zamora: COAL-Delegación de Zamora.

Iturgaiz Ciriza, Domingo (2001): "Memoria y arquitectura sacra. Recuerdos y vivencias en torno a la construcción del santuario de La Virgen del Camino (León)”. En: Fernández-Cobián, Esteban (coord.): Fray Coello de Portugal, dominico y arquitecto. Madrid: Fundación Antonio Camuñas-San Esteban, pp. 61-100.

Otxotorena Elizegi, Juan Miguel (Dir.) (2006): Fray F. Coello de Portugal. Santuario de la Virgen del Camino. Pamplona: Escuela Técnica Superior de Arquitectura de la Universidad de Navarra.

Piñuela Ximénez, Antonio (1987): Descripción histórica de la ciudad de Zamora, su provincia y Obispado. Zamora: Instituto de Estudios Zamoranos Florián de Ocampo.

Rabasco, Pablo (2017): “Carlos Arniches: Algallarín y Gévora, los proyectos para el Instituto Nacional de Colonización”. En: Rabasco, Pablo/Domínguez Ruz, Martín (eds.): Arniches y Domínguez. Madrid: Museo ICO y Ediciones Akal, pp. 166-185.

Urrutia, Ángel (1997): Arquitectura española. Siglo XX. Madrid: Cátedra. 


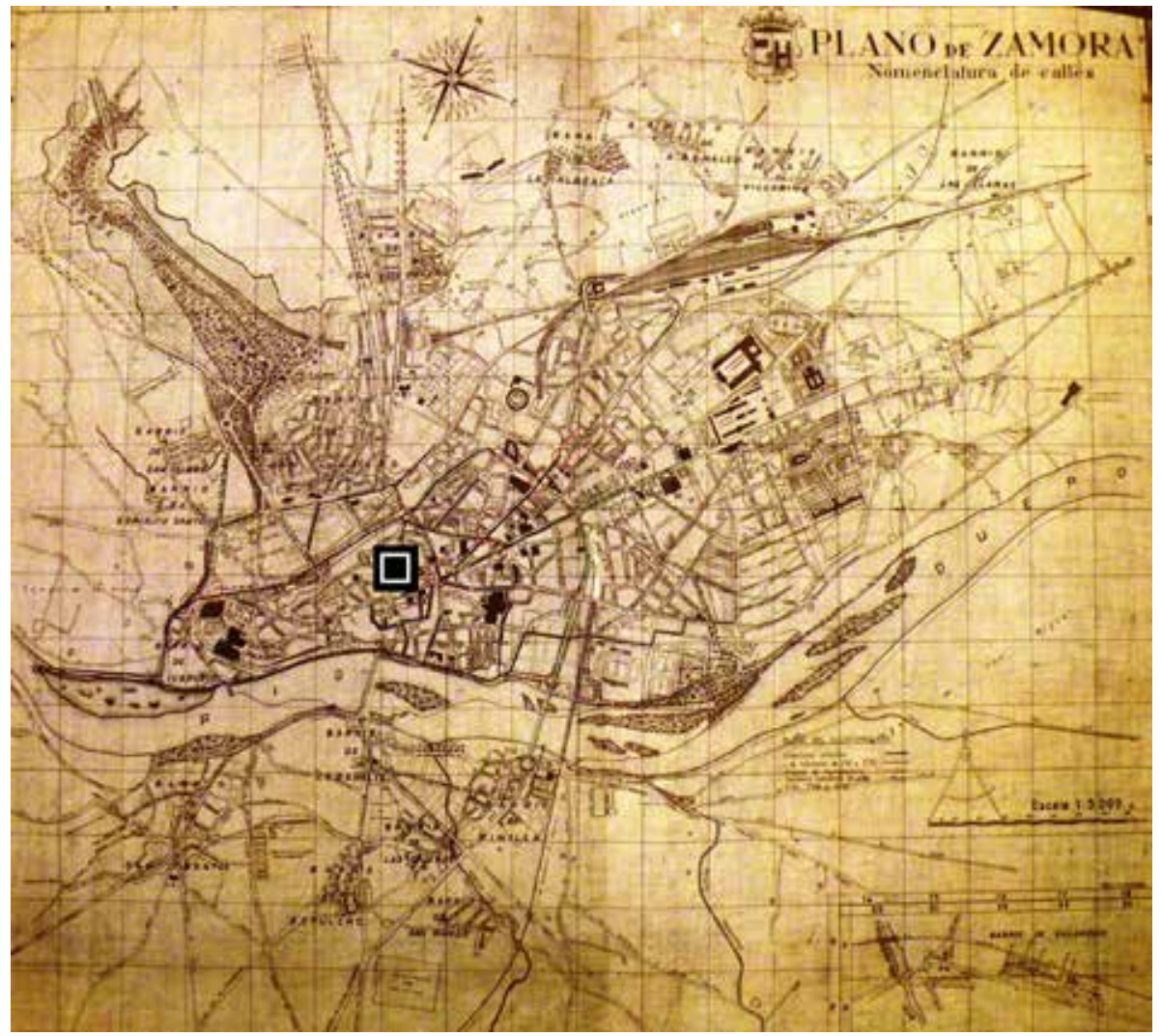

Figura 1: Plano de situación. Elaboración del autor.

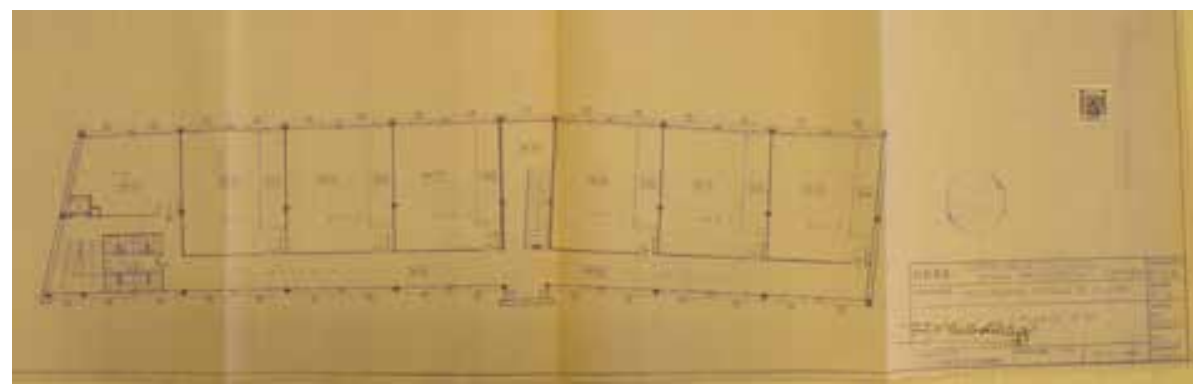

Figura 2: Coello de Portugal, Plano de planta general. Centro Benéfico-Social Divina Providencia, 1964, Zamora, AHPZa. DPV. 70/24. 


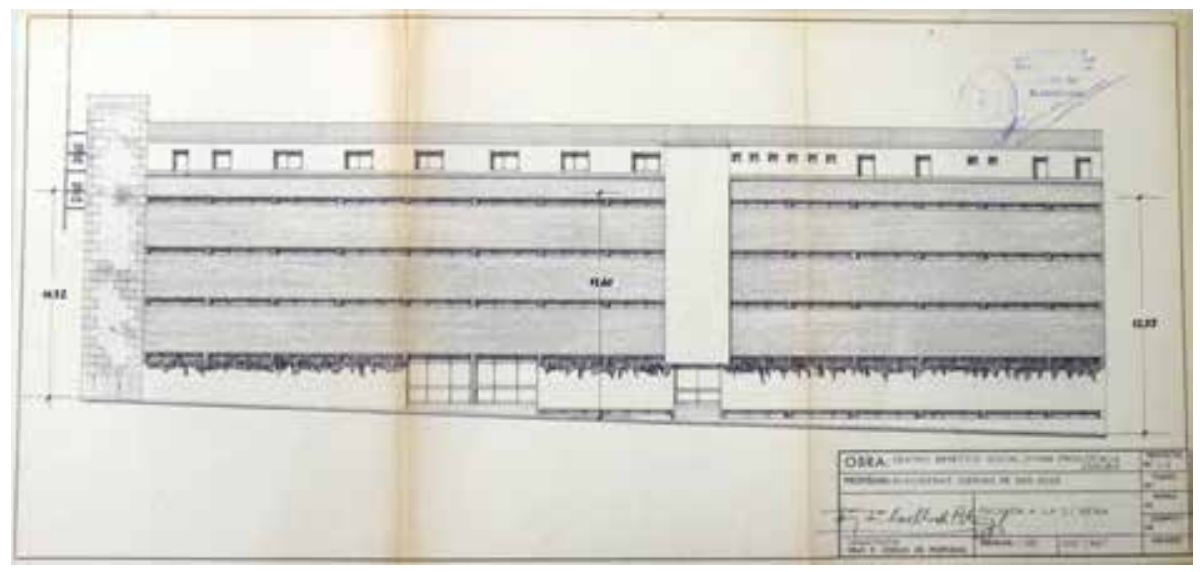

Figura 3: Coello de Portugal, Plano modificación de la fachada principal. Centro BenéficoSocial Divina Providencia, 1967, Zamora, AMZa. OyU. OM/795/66.

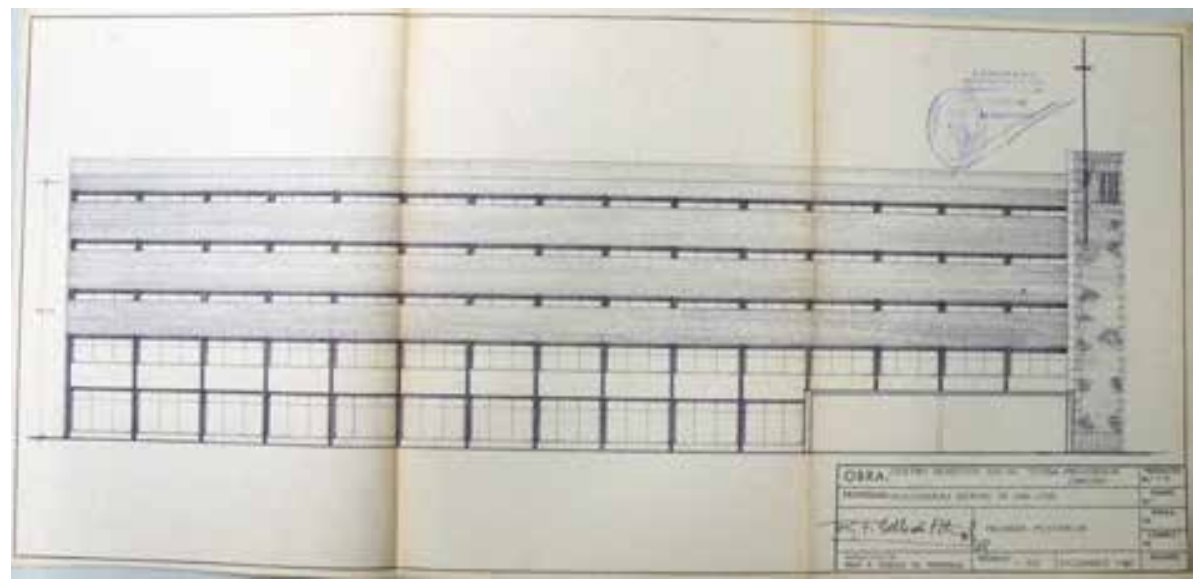

Figura 4: Coello de Portugal, Plano de la modificación de la fachada posterior. Centro Benéfico-Social Divina Providencia, 1967, Zamora, AMZa. OyU. OM/795/66. 


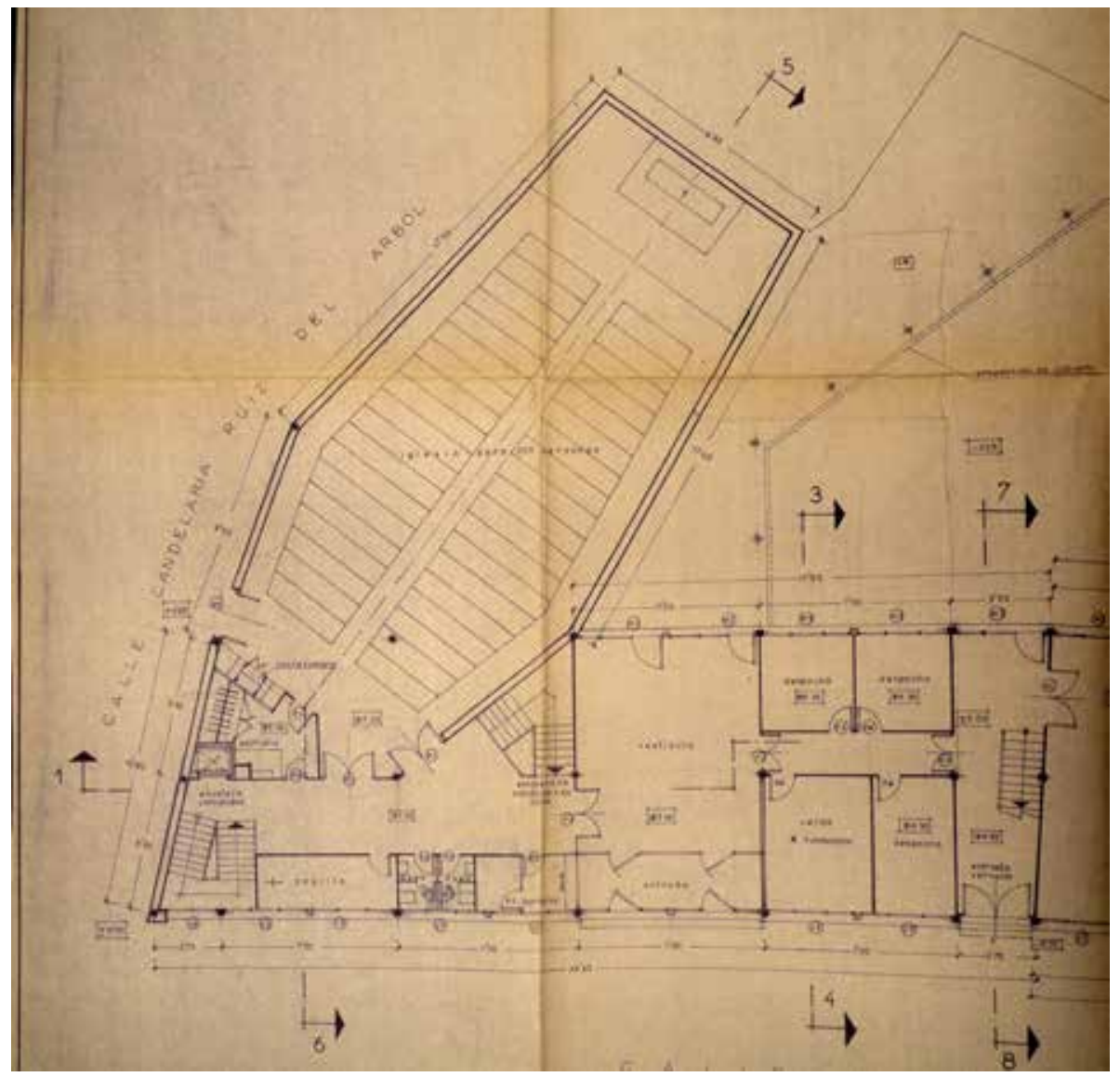

Figura 5: Coello de Portugal, Planta de la capilla. Centro Benéfico-Social Divina Providencia, 1964, Zamora, AHPZa. DPV. 70/24. 


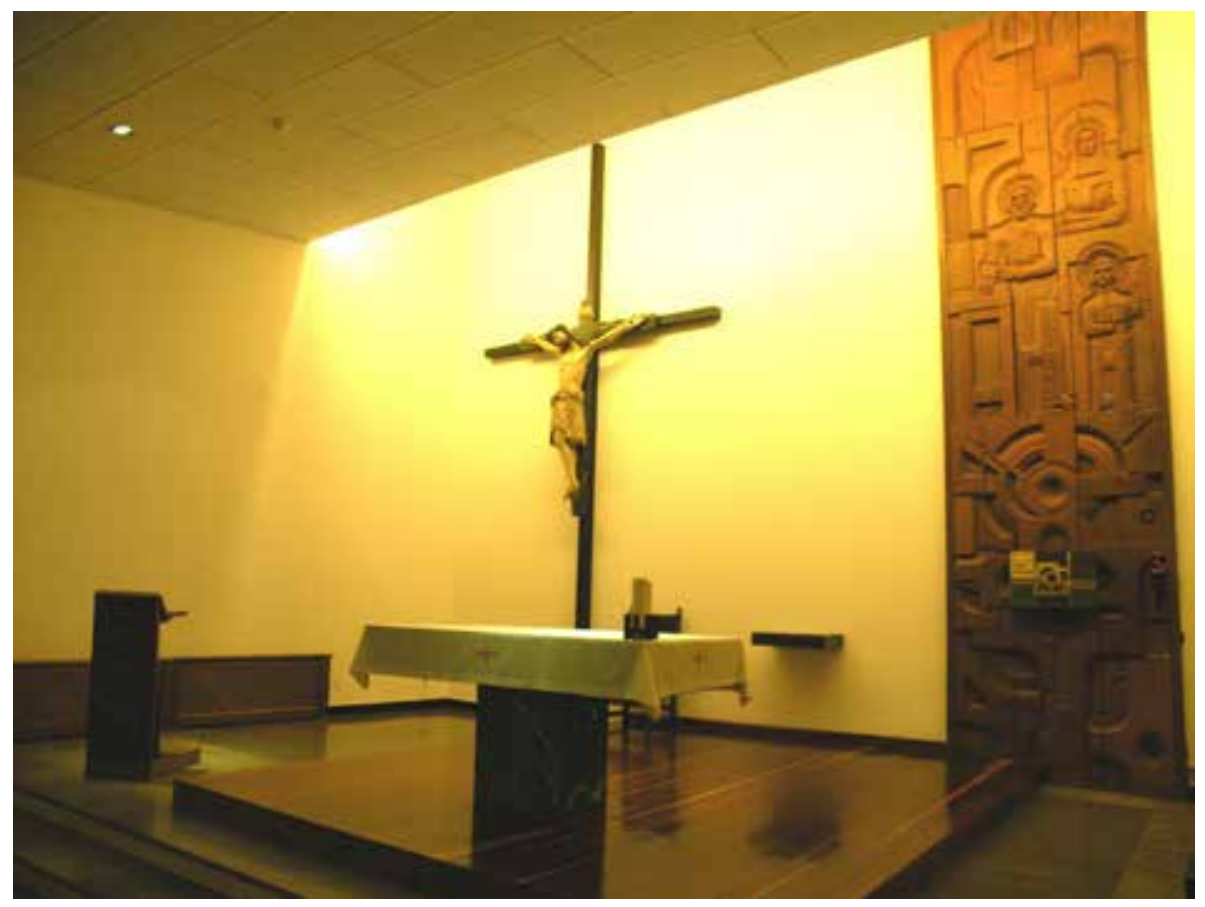

Figura 6: Rafael Ángel García-Lozano, Presbiterio, 2020, Zamora. 


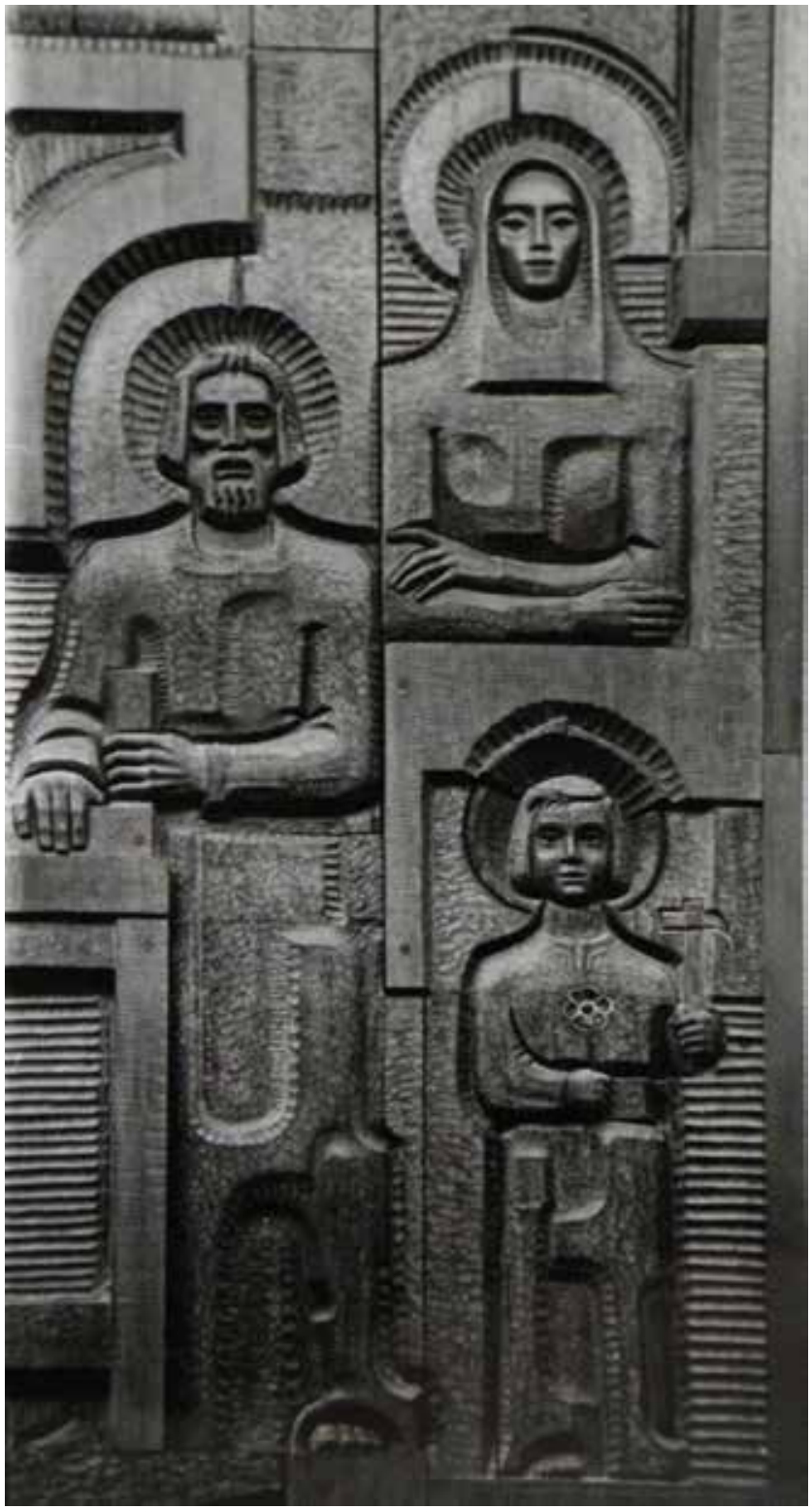

Figura 7: Tomás Crespo Rivera, Detalle del retablo, 1969, Zamora, Colección Tomás Crespo Rivera. 


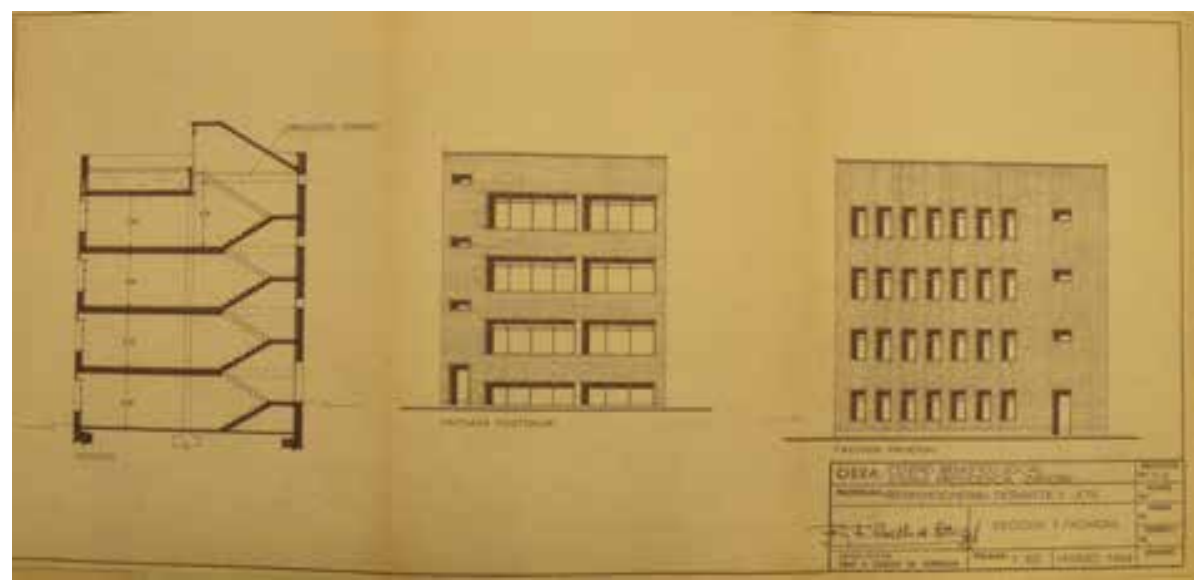

Figura 8: Coello de Portugal, Edificio en la calle Orejones, 1968, Zamora, AHPZa. DPV. 95/02. 